\title{
Effects of Airline Industry Growth on Pilot Training
}

\section{Viktor Valenta ${ }^{1 *}$}

${ }^{1}$ Czech Technical University in Prague, Faculty of Transportation Sciences, Prague, Czech Republic

*Corresponding author: Czech Technical University in Prague, Faculty of Transportation Sciences, Horská 3, 12801 Prague, Czech Republic, Email: valenvik@fd.cvut.cz

\begin{abstract}
The rapid airline growth in recent years sparked debates about global pilot shortage. Interest of talented individuals to join the aviation industry may be affected by unstable remuneration and rising cost of training. This article evaluates pilots supply and demand. The cost of initial pilot training is compared between 2007 and 2017. The airline industry growth in the last decade is described and collated with evolution of labor cost and pilots' pay. Increasing pilot demand puts pressure on efficiency of training. Current training methods are reviewed. A development of new strategies is suggested in order to meet airline industry needs.
\end{abstract}

\section{Keywords}

pilot training; pilot shortage; competency-based training; ATPL

\section{Introduction}

Air transport is a fast and reliable way of transporting both passengers and freight. Even though air traffic nearly doubled in the last decade, the number of major accidents did not rise. Safety is the paramount aspect of aviation. All personnel receive extensive training in order to maintain excellent safety record. Airline industry understands that training is an essential element of operations and not just an expense. However, there is still a strong pressure for effective use of resources. Airlines generally do not sponsor initial training for their future pilots. The cost of initial pilot training is covered by trainees. They are not employed during the training and only after graduation from a flight school they can apply for a pilot job. If successful during assessment, the newly-graduated pilots receive type rating training specific to the assigned aircraft type. The last step is an operator conversion course: newly-hired pilots study company policies and participate in line flying under the supervision of a captain-instructor to get thoroughly familiar with company procedures and the area of operation. Initial training is expected to provide a sufficient basis for follow-up training. This article deals with airlines' perception of initial training and aims to determine whether it meets their needs.

Rapid airline growth leads to a higher demand for pilots. Recently, attention has focused on the so-called global pilot shortage. Increasing demand for pilots brings new business opportunities for training organizations but rises concerns among airlines and regulators. Many training organizations focus only on producing more pilots and do not assess how their graduates adapt to the airline industry.

Cost-cuttings lead to a deterioration of the working conditions for some pilots. The rising cost of initial pilot training and possibly a low return on investment may discourage some candidates from pursuing an airline pilot career. The effects of hiring practices and starting salaries are analyzed in this article.

\section{Training Cost}

A survey of training cost has been performed and cost comparisons between 2007 and 2017 have been attempted. Table 
1 shows the average price of initial professional pilot training from zero experience to ATPL frozen level (this includes ATPL theoretical knowledge instruction, flight training to Commercial Pilot License with Multi-Engine Instrument Rating and Multi-Crew Cooperation Training). Fees and taxes have been included. Euro exchange rates published by the European Central Bank for the respective period have been applied. All values are rounded to hundreds of Euros.

In 2007, the average cost of an integrated ATPL(A) course in the Czech Republic was $€ 37,100$. The average is based on the list prices from three major flight training organizations in the Czech Republic and shows a standard deviation of $€ 900$. Over a ten-year period, the average cost rose to $€ 57,700$ in 2017. The 2017 average is based on the list prices from four major approved training organizations and shows a standard deviation of $€ 15,000$.

In 2007, CASA published a report [1] which compares the training cost from ab-initio to CPL/ME/IR in several regions. The average cost in the United States and the United Kingdom was $€ 33,500$ (standard deviation $€ 10,500$ ) and $€ 51,400$ (standard deviation $€ 3,800$ ), respectively. This report did not asses the cost of Multi-Crew Cooperation Training (MCC). A JAA MCC course was available for approximately $€ 3,000$. Converting an FAA certificate to a JAA license incurred the cost of approximately $€ 2,000$. The total training prices are shown in Table 1.

In 2017, the average cost of an integrated ATPL(A) course in the UK increased to $€ 101,100$ (standard deviation $€ 9,600$ ). This average is based on the list prices from three key approved training organizations across the UK. An average cost of training in the US in 2017 has not been established. Conversion of an FAA certificate to an EASA license under the requirements of Commission Regulation (EU) No. 1178/2011 is a lengthy and costly process, which effectively hinders European candidates from attending FAA courses. In addition, as a result of the Buffalo Crash, FAA adopted a new first officer qualification (FOQ) rule. From 2014, first officers in the US are required to hold an ATP or R-ATP certificate. This caused a major change to US flight training programs which now often include instructor training and instructor placement to reach the required experience level. From 2007 to 2017, the training cost average in the Czech Republic and the UK increased by $55.5 \%$ and $85.8 \%$, respectively. This is a significantly steeper rise than the inflation rate over the same time period: EU Harmonized Index of Consumer Prices published by Eurostat is showing a $13.8 \%$ increase.

The cost of a type rating course has not been determined because it greatly varies depending on aircraft type and training provider. Many airlines in Europe require newly-hired pilots to self-fund their type rating. Some airlines provide discount rates or even sponsor the entire course in return for a training bond.

\section{Airline Industry Growth}

IATA data [2] indicate that global commercial airlines transport capacity has been rising steeply since 2009, as shown in Fig. 1. Recent forecasts of airline personnel demand (most notably [3] and [4]) use predicted fleet size growth as a primary parameter. Although the numbers of aircraft and aircraft utilization provide the best indicators for predicting pilot demand, transport capacity has been chosen for the purpose of this study because it can be easily correlated with expenses. Freight and passenger transport Available Tonne-Kilometers (atk) have been combined. As the weight load factor has remained relatively constant at around $68 \%$ since 2010 , a solid growth of carried revenue load can be observed.

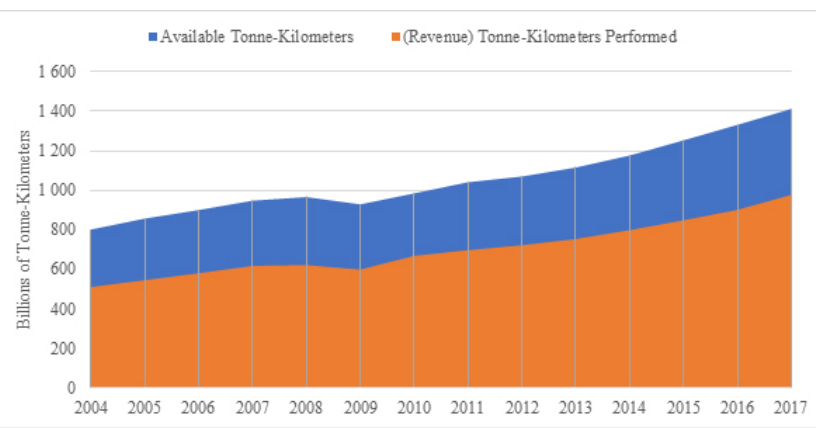

Figure 1. Global commercial airlines transport capacity expressed in Available Tonne-Kilometers (atk) and total revenue load carried expressed in Tonne-Kilometers Performed (tkp). Data derived from [2]

However, the Great Recession during the late 2000's initiated an unceasing series of cost-cutting measures across the airline industry. The most discussed initiatives are fuel savings and labor cost reduction. The jet fuel price peaked in 2008, as shown in Fig. 1. Based on IATA data [2], the jet fuel prices has been highly volatile and constituted between $20 \%$ and $36 \%$ of total commercial airline expenses in the period from 2008 to 2017.

\section{Labor Cost}

An analysis of the global labor cost appears to be very difficult. This can be attributed to the reduction of flight deck crews to two pilots which was initiated in the 1990's in Europe and North America and continued throughout the 2000's. The rapid expansion of low-cost carriers in the early 2000's adds to complexity. No global labor cost data were published by IATA prior to 2013. By combining IATA fuel expenses data and the Zuidberg's study [5] of airlines' annual reports from 2007 to 2010, it can be estimated that labor cost accounts for approximately $20 \%$ of the total expenses. A more detailed look into labor cost has been attempted by CAPA - Centre for Aviation [6, 7]: in 2012, labor cost ranged from 4.7 c/atk in the low-cost airline segment, through 6.0 c/atk in the Middle East, up to 38.9 c/atk in European legacy airlines. 
Table 1. Average price for initial professional pilot training (EUR)

\begin{tabular}{l|ccc}
\hline & Czech Republic & United Kingdom & United States \\
\hline 2007 & 37,100 & 54,400 & 38,400 \\
\hline 2017 & 57,700 & 101,100 & N/A \\
\hline Change & $+55.5 \%$ & $+85.8 \%$ & N/A \\
\hline
\end{tabular}

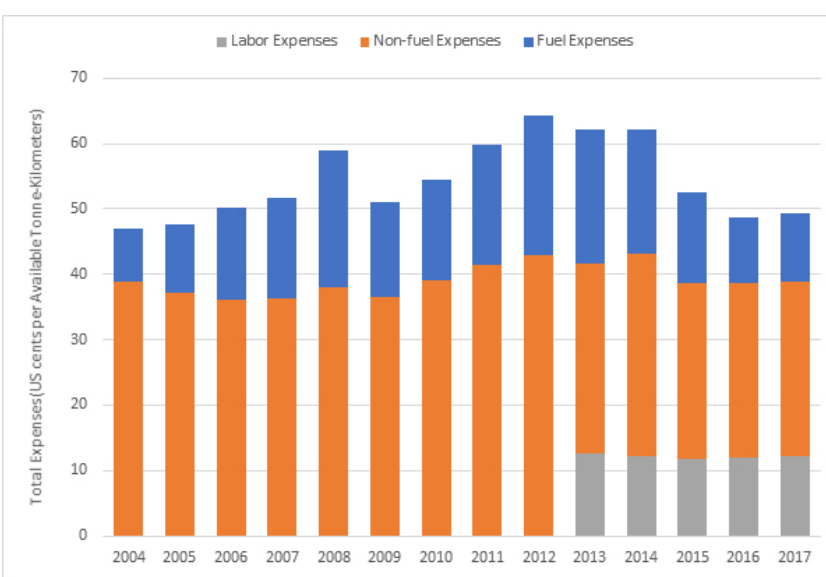

Figure 2. Global commercial airlines expenses per Available Tonne-Kilometers. Data derived from [2]. Labor expenses are included in non-fuel expenses prior to 2013 .

No significant trend in non-fuel expenses can be observed, although airline employee salaries have been rising since 2011. The Airline Cost Management Group (ACMG) report [8] shows that pilots account for $12 \%$ of airline staff but form $29 \%$ of labor expenses. This disproportion is the obvious source of focused attention. General public impression supported by media coverage is that pilots are earning very high salaries. However, this topic is far more complicated. A simple look at the readily available industry-wide (e.g. US Bureau of Labor Statistics or UK Education and Skills Funding Agency) may provide misleading results, because senior captains at legacy airlines indeed earn high salaries. Making an informed decision about career goals may be very difficult.

Although the US airline job market is quite unique, it may provide a valuable lesson for the global industry. In 2014, first officer starting salaries among US regional airlines were below the $\$ 25,000$ ( $€ 1,500$ per month) mark and many were struggling to meet the hiring needs. In 2015, Airline Pilot Association (ALPA) president Captain Tim Canoll stated, "the pilot shortage cited by US regional airlines is really a pilot pay shortage". This statement was backed by Byrne's survey [9] which showed: "a starting salary of the $\$ 40,000$ to $\$ 45,000$ range would virtually double the current regional pilot workforce". Lutte's follow-up research [10] revealed an increase in starting salaries to an average of $\$ 51,400$ ( $€ 2,700$ per month) in 2017 and pointed out: "Regional airlines are generally meeting hiring needs but there is concern for sustainability of these hiring levels for the long term."

European pilot job market is different as regional airlines do not usually supply pilots to major airlines; also, corporate and business aviation sectors are very small compared to the US. In 2015, an extensive survey of pilot employment in Europe [11] showed that European pilots tend not to switch employers and all airlines regardless of business type can serve as pilots' first employer. Low-cost carriers have the highest number of newly graduated pilots; however, this can be attributed to the rapid growth of this segment.

European new-hire airline pilot's first-year salary in 2007 ranged from $\$ 29,600$ (€1,800 per month) to $\$ 59,200$ (€4,900 per month). Pilot hiring virtually ceased in 2009 and shortly afterwards pay-to-fly schemes emerged. Several agencies offered placements to gain airline experience where newly graduated pilots were required to pay sums in excess of $€ 25,000$ in addition to type rating costs. In 2011 a strong hiring demand resumed with starting salaries as low as $\$ 13,500$ (€800 per month). Current (2017) starting salaries vary from $\$ 19,800$ (€1,100 per month) to $\$ 67,800$ ( $€ 3,600$ per month), i.e. slowly reaching the pre-2009 level. However, industrywide salary average has already exceeded the pre-2009 value according to the Steer study [12].

\section{Pilot Demand}

With such volatile salaries it is difficult to calculate the return on investment in training and attract talented candidates. The Byrne's study [9] showed that only one third of accepted students at Embry-Riddle Aeronautical University (ERAU) enrolled in pilot training and approximately $65 \%$ pilot entrants completed the four-year training program. Lutte's and Lovelace's research (2013) [13] revealed that $11 \%$ of students changed their career goals and decided not to pursue airline pilot careers. The reasons given included concerns over the increased training cost (due to FOQ rule change), salary and lifestyle.

Flight schools often provide candidates with potential earnings estimates (e.g. [14]) or cost comparison with different fields of study (e.g. [15]). Despite the fact that such documents serve primarily for marketing purposes and should be used with caution, they can provide at least some insight.

A hiring slowdown after the Great Recession forced newlygraduated pilots to accept mediocre conditions for their first employment. Present hiring needs are covered due to improving terms and partially by the backlog of pilots accumulated during the slowdown. The question remains for how long such a situation is sustainable. The pool of available pilots is slowly diminishing, since the numbers of students enrolled in training are not rising as quickly as the demand.

Initial professional pilot training usually takes between 18 to 36 months. It usually takes three to six years on-job first 
officer experience to upgrade to a captain position. The 2014 first officer shortage may thus soon become a captain shortage. A captain shortage is much more difficult to deal with.

\section{Training Methods}

Concerns over the dropping standards of pilot training have been voiced. Although no such evidence has been found in Europe or North America, training deficiencies and suspected falsification of training records cited in the Kazan Crash [16] as well as fake licenses scandals in Asia [17] should be treated seriously. Authority oversight should not diminish with the increasing use of the safety management system (SMS). The SMS is now widely used in the airline environment; however, it has not reached its full potential within training institutions. The SMS is a great tool for gathering data, but it cannot substitute audits.

Initial pilot training is based on the principles developed during the first half of the last century. Very strong emphasis is put on manual flying skills. This was essential in the days prior to autopilots. Manual flying skill still does not lose any of its vital importance, but other skills need to be mastered by future airline pilots too. A review of recent accidents shows that mismanagement of automation is cited as one of the leading causes. Today's general aviation aircraft used in basic training are equipped with avionics as advanced as the avionics in modern transport jets. Rigid training syllabi prevent the use of modern equipment to its full potential. Different levels of automation and reversion to manual flight can be practiced on many general aviation aircraft and save valuable time in expensive full flight simulators during type rating training courses. Type rating training courses should be primarily used to familiarize pilots with type-specific aircraft systems and not to introduce new competencies. Type rating courses can only be used to improve competencies, since they are relatively short in duration.

It is a common phenomenon that newly graduated pilots struggle with situational awareness and application of procedures when they start their initial airline experience. However, their preparation can be improved by properly addressing the complexity of airline operations during theoretical knowledge instruction. Goyer [18] notes that ground school training often becomes just "checking the boxes" and fails to explain the basics of real life operations.

In the past pilots often faced inflight failures and managed to learn proper workload management and decision-making without systematic guidance. Today, pilots can get through their entire career without facing a single major emergency. Technological advancement makes aircraft extremely reliable and leads to complacency. Real life emergencies are always accompanied by an element of surprise. Simulators training can familiarize pilots with system failures. Such familiarity can possibly reduce startle effects for pilots confronted with a known malfunction inflight. However, it is difficult to induce extreme pressure and life-threatening fear in simulator environment.
An interesting fact emerged from the Lutte's study [10]: raising experience requirements for first officers (FOQ rule) did not help to deliver pilots with better skills. A more experienced pilot does not necessarily mean a better pilot. Candidates are required to acquire more flight hours after initial training and prior to joining an airline. These hours are often flown without any supervision and can lead to development of bad habits; additional training after joining an airline is often required in order to reverse these bad habits [10].

Monitoring of training effectiveness is required to improve training. The vast majority of training organizations lose track of their students after their final skill test. Simply assessing success rate at skill tests does not provide enough data to adjust training syllabi. Leoff [19] estimates that " $50 \%$ of pilots graduating from the current EASA pilot training [are] assessed by airlines [as having] insufficient competencies for employment." Unfortunately, initial pilot training must be fairly versatile because commercial license pilot holders may want to seek a job at crop dusting as well as at an airline; and obviously, each career path will require a slightly different set of competencies. Training organizations should look for feedback from operators which employ their graduates.

Many airline affiliated training programs were suspended in the early 2000's as parts of cost-cutting measures. In recent years such programs started reappearing and have a great potential of delivering training which is tailored to airlines' needs.

Multi-crew pilot license (MPL) training is an initiative which allows training organizations and airlines to design a truly competency-based training (CBT) program from scratch. MPL has met with mixed reactions - it was seen by many stakeholders as a desperate attempt to reduce training time and cost, which however was not true. MPL programs are as long as integrated ATPL programs and are often even more expensive because of the use of full flight simulators. The fact is that training hours on aeroplanes have been dramatically reduced. In a survey of experience with MPL, Wikander and Dahlström [20] discovered that the CBT implementation was only a partial success. Although MPL managed to improve some competencies, it raised additional concerns about the inability to simulate high stress and fear scenarios which can be experienced in real life.

\section{Conclusion}

Improving remuneration is only one of the measures airlines could take to deal with the staffing problem. The aviation industry should attempt to attract new talents and focus on other life style issues (e.g. rostering patterns and pilot fatigue.) Calculating the return of investment in pilot training during the first few years of pilot employment poses significant challenges and may cause prospective students to seek other opportunities.

The airline industry growth and increasing pilot demand should lead to improvements in initial pilot training. The current training methods are rigid and do not fully address airline 
needs. It has been shown that type rating training courses and operator conversion courses are used to train competencies which should already be acquired during initial training. This increases the costs of airlines and causes frustration among trainees and instructors. Implementing competency-based training (CBT) principles may help to optimize training hours and syllabi. ICAO thoroughly defined the core competencies; however, these definitions need to be well understood and used by training organizations. The mastering of CBT is the first step. Training organizations must seek more information on how their graduates adapt to commercial operations. The airline industry can generate data about training deficiencies. Further research is required to define data sets which may provide a basis for implementing evidence-based methods in initial pilot training.

\section{Acknowledgments}

This article was supported by the Grant Agency of the Czech Technical University in Prague, grant No. SGS17/155/OHK2/2T/16.

\section{References}

[1] Report on comparison of the cost of flying training between australia, usa, new zealand and the uk, 2007.

[2] IATA. Airline industry economic performance. 2018.

[3] CAE. Airline pilot demand: 10-year view. 2017.

[4] Boeing. Pilot technician outlook 2018-2037. 2018.

[5] J. Zuidberg. Identifying airline cost economies: An econometric analysis of the factors affecting aircraft operating costs. Journal of Air Transport Management, 40: 86-95, 2014.

[6] CAPA. European airlines' labour productivity. oxymoron for some, vueling and ryanair excel on costs. 2013.

[7] CAPA. Unit cost analysis of emirates, iag virgin; about learning from a new model, not unpicking it. 2014.

[8] IATA. Airline cost management group (acmg) report fy 2013 , enhanced version. 2014.

[9] K. Byrnes. Pilot employment motivation. Airline Pilot Shortage? Myths, Facts, and Solutions, 2015.

[10] R. Lutte. Pilot supply at the regional airlines: Airline response to the changing environment and the impact on pilot hiring. Journal of Aviation / Aerospace Education Research, 27(1):1-22, 2017.

[11] L. Valcke Y. Jorens, D. Gillis and J. De Coninck. Atypical forms of employment in the aviation sector. In European Social Dialogue, 2015.
[12] Steer Davies Gleave. Study on employment and working conditions in air transport and airports. 2015.

[13] R. Lutte and K. Lovelace. Airline pilot supply in the us: Factors influencing the collegiate pilot pipeline. Journal of Aviation Technology Engineering, 6(1):53-61, 2016.

[14] CATC. Výcvikové programy pilotů typu ab initio. Career Day, Prague, 2017.

[15] Flying Time Aviation. Degree versus pilot training: How do they compare? 2016. URL http://wWw. ftaglobal.com/fta-news/degree-versuspilot-training-how-do-they-compare.

[16] S. Hradecky. Crash: Tatarstan b735 at kazan on nov 17th 2013, crashed on go-around. The Aviation Herald, 2015. URL http://avherald.com/h? article $=46 \mathrm{~b} 9 \mathrm{ecbc} / 0022$.

[17] A. Kotoky. You can get a pilot license in india after just 35 minutes in air. Bloomberg, 2015. URL https : / / wwW . bloomberg . com/news/articles/2015-06$01 / p i l o t s-q u a l i f i e d-t o-f l y-i n-i n d i a-$ after-just-35-minutes-in-air.

[18] R. Goyer. Going direct: To push or to pull. Flying, 2011.

[19] T. Leoff. Strategic option for pilot training innovation. Workshop on Area 100 Knowledge, Skills Attitudes: theoretical knowledge courses for the ATPL, MPL and CPL, 2018.

[20] R. Wikander and N. Dahlström. The Multi-crew Pilot License Part II: The MPL Data - Capturing the Experience. Lund University School of Aviation, Ljungbyhed, 2016. 